\section{Commentary: Has pulmonary artery catheter ship sailed?}

\author{
Elena Ashikhmina, MD, PhD
}

There appears to be a persistent enthusiasm for a continual investigation into whether the use of pulmonary artery catheter (PAC) leads to reduced morbidity and mortality in critically ill patients. Perhaps no other monitoring tool enjoys being consistently trendy for several decades. A wide spectrum of opinions can be found in the literature. Some authors already have written an obituary to PAC, ${ }^{1}$ some argue that PAC is immortal, and others believe that "in medio virtus," finding PAC more alive than dead. ${ }^{3}$ Another category of publications, similarly to Brown and colleagues, focuses on certain patient populations, relies on thorough statistical analysis, and avoids generalized and emotional statements. ${ }^{4,5}$

It has been suggested that the information provided by PAC might be inaccurate, insertion is associated with complications, and the rate of misinterpretation of data is alarming. ${ }^{1}$ In addition, many demonstrated no improved mortality in patients with PACs. ${ }^{6}$ In turn, advocates of PAC emphasize the importance of the ability to measure pulmonary artery pressure, including occlusion pressure and mixed venous saturation, invaluable in the management of patients with marked myocardial dysfunction and pulmonary hypertension. ${ }^{3}$

Because of "limited and conflicting data," Brown and colleagues $^{5}$ took another look at the PAC in the setting of cardiac surgery. They studied 11,820 patients, and identified 3519 propensity-matched pairs managed with and without PAC. They found that PAC use was not associated with improved operative mortality. It was concluded that "PAC may have limited benefit in cardiac surgery." The manuscript is very well written and convincing, but it is important not to overlook the supplemental data. Study patients had preserved left ventricular ejection fraction $(>40 \%)$,

From the Department of Anesthesiology and Perioperative Medicine, Mayo Clinic, Rochester, Minn.

Disclosures: The author reported no conflicts of interest.

The Journal policy requires editors and reviewers to disclose conflicts of interest and to decline handling or reviewing manuscripts for which they may have a conflict of interest. The editors and reviewers of this article have no conflicts of interest.

Received for publication Jan 29, 2021; revisions received Jan 29, 2021; accepted for publication Feb 1, 2021; available ahead of print Feb 5, 2021.

Address for reprints: Elena Ashikhmina, MD, PhD, Department of Anesthesiology and Perioperative Medicine, Mayo Clinic, 200 First St SW, Rochester, MN 55905 (E-mail: ashikhmina.elena@mayo.edu).

J Thorac Cardiovasc Surg 2022;164:1978-9

$0022-5223 / \$ 36.00$

Copyright (c) 2021 by The American Association for Thoracic Surgery

https://doi.org/10.1016/j.jtcvs.2021.02.003

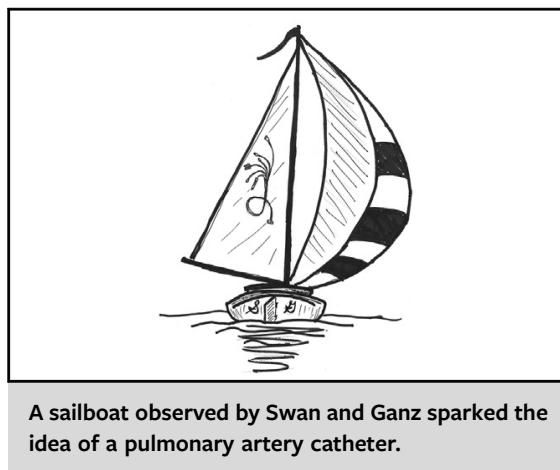

CENTRAL MESSAGE

In patients with preserved ejection fraction and a shorter

bypass, continuous monitoring of hemodynamic parameters by pulmonary artery catheter did not improve operative morbidity or mortality.

reasonably short ischemic time (around 80 minutes), and the majority (around 90\%) had primary sternotomy. Therefore, no conclusions can be extrapolated to patients with low ejection fraction, prolonged cardiopulmonary bypass time, and repeat cardiac surgery.

This study raises awareness that one should be more conscious when deciding "to throw in a Swan" in a "bread-and-butter" cardiac case. As a compromise, an introducer instead of a regular central line catheter can be inserted for central access and PAC can be floated later if needed. Many cardiac anesthesiologists have to cleverly balance their own thoughts and surgical preferences. The "habitual" placement of PAC should be minimized based on data provided by Brown and colleagues. ${ }^{5}$

It is possible to safely get the patient through complex cardiac operation without PAC. In congenital cardiac surgery, PAC often is not an option. In the dire circumstances of low cardiac output (sometimes of a single ventricle) or acute pulmonary hypertension, PAC could help to diagnose and intervene, but instead one must fully rely on signs of perfusion adequacy, not a straightforward task.

In conclusion, PAC is an intricate tool. It can be a burden when everything goes well, but it could be very helpful when things get tricky. Fortunately, the PAC ship has not sailed; on the contrary, the anchor seems dug in, and that must be fixed. 


\section{References}

1. Marik PE. Obituary: pulmonary artery catheter 1970 to 2013. Ann Intensive Care. 2013;3:38.

2. De Backer D, Vincent JL. The pulmonary artery catheter: is it still alive? Curr Opin Crit Care. 2018;24:204-8.

3. Vincent JL, Pinsky MR, Sprung CL, Levy M, Marini JJ, Payen D, et al. The pulmonary artery catheter: in medio virtus. Crit Care Med. 2008;36: 3093-6.

4. Schwann NM, Hillel Z, Hoeft A, Barash P, Möhnle P, Miao Y, et al. Lack of effectiveness of the pulmonary artery catheter in cardiac surgery. Anesth Analg. 2011; 113:994-1002.

5. Brown JA, Aranda-Michel E, Kilic A, Serna-Gallegos D, Bianco V, Thoma FW et al. The impact of pulmonary artery catheter use in cardiac surgery. J Thorac Cardiovasc Surg. 2022;164:1965-73.e6.

6. Rajaram SS, Desai NK, Kalra A, Gajera M, Cavanaugh SK, Brampton W, et al Pulmonary artery catheters for adult patients in intensive care. Cochrane Database Syst Rev. 2013;2013:CD003408. 